\title{
The Creation of a Registration and Information Database for Cultural Heritage in Mongolia
}

\author{
Galbadrakh Enkhbat
}

\begin{abstract}
Under the "National Project for Digitization of Cultural Heritage" started in 2005, a total of 42 organizations are involved in the registration and information state database of cultural heritage, using $\mathrm{RCH}$ (Registration of Cultural Heritage) software. So far, 45,645 names and 65,211 movable objects have been registered. For immovable historical and cultural properties, the registration is conducted using RICH (Registration of Immovable Cultural Heritage) software. So far, a total 32,124 historical and cultural immovable properties from 3,100 cultural sites in 15 provinces have been registered. Registration for ICH (Intangible Cultural Heritage) covers 329 soums (sub-provinces) and 9 districts, and 7,206 individuals identified as ICH bearers. In 2014, the "National Project for Digitization of Cultural Heritage-2" was approved, aiming to register and document cultural heritage, to take control of conservation and preservation of cultural heritage, to create a digital database for tangible and intangible cultural heritage, and to improve the system used for registration and information database of cultural heritage.
\end{abstract}

\section{Introduction}

By the consent of the People's Great Khural (the unicameral Parliament of Mongolia), the "Law on the Protection of Cultural Properties of the People's Republic of Mongolia" was adopted in 1970. In 1994, after several amendments, the law was adopted as the "Law on the Protection of Historical and Cultural Properties" by the State Great Khural and a new chapter related to the creation of a registration and information state database and its registration procedures was included.

According to the law, the registration and information state database will include research definitions, research reports, photographs, slides, audio and video recordings, and brief reports on restoration. The registration and information database is defined as having the purpose of classifying, conserving, and inheriting the heritage.

\footnotetext{
G. Enkhbat $(\bowtie)$

Center of Cultural Heritage, Sukhbaatar square -3, Cultural palace F- 2,

Ulaanbaatar -11, Mongolia

e-mail: enkhbat@monheritage.mn
} 
The database is also mandated to assist in the full recovery of cultural heritage elements when they are damaged, destroyed, or forgotten.

In 2001, several amendments were made to the 1994 "Law on the Protection of Historical and Cultural Properties" with articles added on the protection of intangible cultural heritage, and the law was renamed the "Protection Law for Cultural Heritage." According to the "Protection Law for Cultural Heritage," cultural heritage is classified as tangible and intangible. Tangible cultural heritage is classified as historical and cultural properties that are immovable and movable. Historical and cultural immovable heritage can be recognized as individual elements or as complexes.

On May 15th, 2014, the "Protection Law for Cultural Heritage" was amended by the State Great Khural.

\section{Registration Form}

In 1996, the first document "Registration form for historical and cultural properties of Mongolia" or form №1 was used to register museum objects, artifacts, and immovable properties in the database of historical and cultural properties.

Based on the revision of the "Protection Law for Cultural Heritage" in 2001, the "Registration form for historical and cultural properties of Mongolia" or form № 1 was amended as the "Registration form for Cultural Heritage of Mongolia" or form №2 by the 56th decision of Ministry of Education, Culture, and Science of Mongolia, in 2006.

However, the registration form did not allow for sufficient time to record enough information about museum objects and immovable properties. Therefore, in 2007, the Ministry of Education, Culture, and Science decreed in order №348 that the form "Registration of Historical and Cultural immovable properties" №1 be used instead. The order was approved and that form was used.

To assist in their required purpose of creating a database of intangible heritage and its bearers, in 2010, registration forms with specific questionnaires related to the registration of tangible heritage (historical and cultural movable and immovable properties) and of intangible heritage were adopted by 541st decision of the Ministry of Education, Culture and Science of Mongolia.

The "Registration form for historical and cultural movable heritage of Mongolia" gathers information using the following 34 questions, including: owner, possessor, address of location, condition, name of heritage, identification number, classification of heritage, decision, types or categories, relevant period, creator, creative skill, material and method, measurement, set, when collected and discovered, damage, decision for protection, purpose of use, common or uncommon status, origin, definition, brief history, restoration condition, reproduced or not, transfers or movement, relevant research, note of attachment, etc.

The "Registration form for historical and cultural immovable heritage of Mongolia" gathers information using 34 questions, including: province, Ulaanbaatar City, soum 
(sub-province), district, owner, possessor, identification number by registration and information database, name of heritage, classification of heritage, administration unit (heritage location), GPS, relevant period, protection condition, decision for protection, complex or not, date of discovery, measurements, protection condition, definition, brief history, relevant research, restoration condition, and note of attachment.

The "Registration form for intangible heritage and its bearers" gathers information according to 28 questions, including: province, Ulaanbaatar Province, soum, district, identification number by registration and information database, expression of intangible cultural heritage ( $\mathrm{ICH})$, information related with $\mathrm{ICH}$ bearer, information related to ICH elements, distribution of ICH elements and bearers, specific, safeguarding, etc.

After the revision of the registration forms, the guidelines and instructions were elaborated and enforced at every level of the registration and information database.

\section{Registration and Information Database}

The Center of Cultural Heritage created the registration and information database of cultural heritage. The center was established in 1988 as the Restoration Studio for Museum Objects. In 1996, in accordance with the 7th decision of the Government of Mongolia, the structure of the restoration studio was changed to the Center of Cultural Heritage and a new unit for the registration and information state database of cultural heritage was established.

The structure of the registration and information state database of cultural heritage is seen below (Fig. 1).

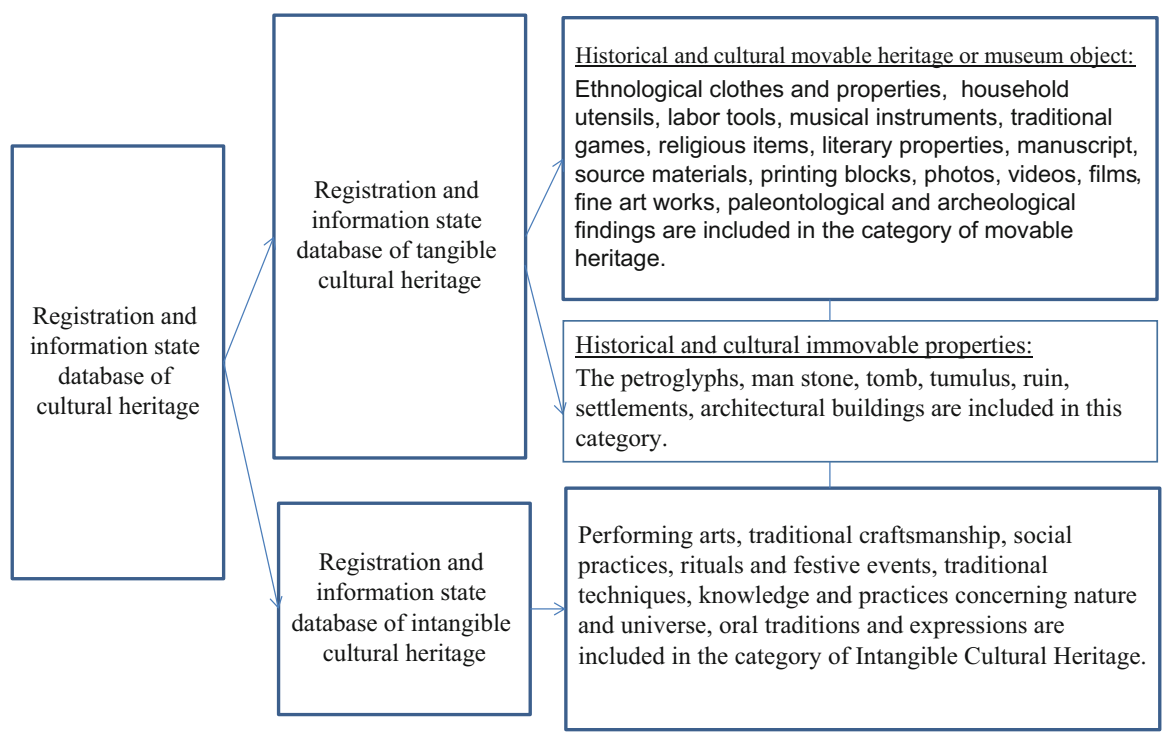

Fig. 1 Structure of the registration and information state database 
Cultural heritage registration database systems include:

- Organization registration database;

- Soum, district registration database;

- Province, capital city registration database;

- Unified state registration database.

Registration and information database components are:

- Paper-based registration and information: The object's general registration, classified registration, and research registration are guided by museum regulations. Registrations are completed using the approved forms for tangible and intangible heritage, and they include a heritage photo, research report, etc.

- Digital registration and information: Software "RCH", "Register", "RICH", digital version of the registration form, CD, DVD, hard disk, and audio and video recordings.

From 1996 to 2005, the registration and information state database received registrations from state and province museums in paper form, but this was not considered successful. The questionnaires did not gather enough information, and the state and province museums had poor internet access and a lack of staff members to complete the work.

The project "Automatic Measuring and Image Recording System for Historic and Cultural Heritage" was implemented by the Center through the support of Japanese Cultural Grant Aid in 1999-2000 (Fig. 2). Under the scope of this project, the Center was provided with computers and camera equipment for the documentation of museum objects, as well as some restoration equipment. Since then, photo documentation work has started in 21 provincial museums and the gathered data have been saved in the registration and information database. It was necessary to
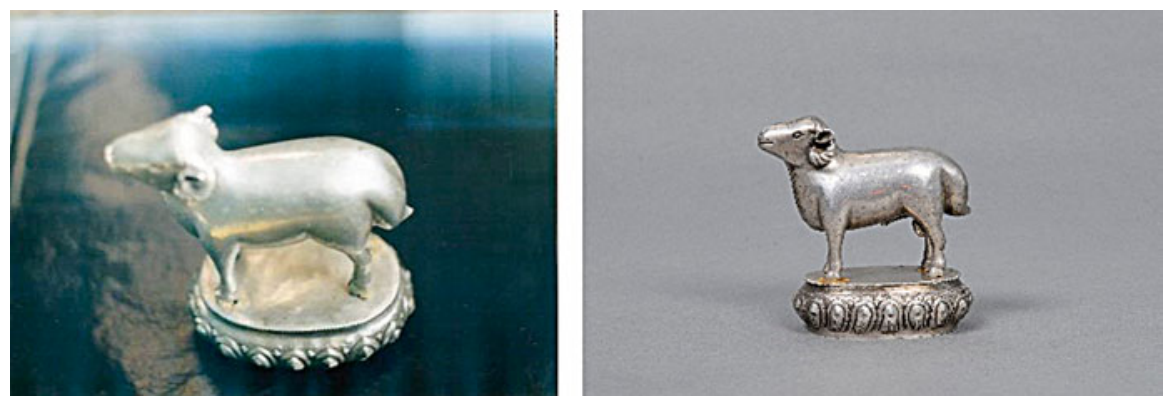

Fig. 2 Photo taken before (left) and after (right) implementation of the project "Automatic Measuring and Image Recording System for Historic and Cultural Heritage" 
provide museums with computer and camera equipment and to introduce new technology into the museums, because their equipment and facilities were previously inadequate for photo documentation of all the objects held in state museums.

Because of this, on December 7th, 2005, the Government of Mongolia in their 244th decision adopted the "National Project for Digitization of Cultural Heritage." The objectives of this project were to enhance the creation of the registration and information database of cultural heritage, to gather all data related to museum objects and historical and cultural properties, to improve the operation of primary registration and information database and systems of databases, and to create a unified state registration and information database.

Aiming to meet the objectives of the project, several measures were taken on human resources and technology. Based on the registration form "Registration form for historical and cultural movable heritage," the software "RCH: Registration of Cultural Heritage" 1.0 was created and installed in 38 museums in 21 provinces. In 2010, the software RCH was revised and RCH version 2.0 was created. These 38 state and provincial museums were provided with the following equipment:

- Computer and UPS (software RCH was installed)

- Printer

- Camera equipment for documentation of museum objects (professional digital camera, two lenses, umbrella, memory card, battery, and charger)

- Network sharing (State and province museums send their registrations to the state database through the internet.)

The new job position of "registration officer" was approved for museums in 2008, and several training workshops were organized for registration officers to provide them with a working knowledge of the $\mathrm{RCH}$ software and the process of registering museum objects.

In accordance with national legislation, museums send their registration to the soum, district, and province levels and to Ulaanbaatar City. The provinces and Ulaanbaatar City communicate with the unified state registration and information database, so there is no need for individual soums and districts to send data to the state.

Since using the software RCH, museum research workers and registration officers have sent details on around 800 objects to the state database, depending on the size of their museum's collection, but this work has been delayed.

The state inventories museum objects every 4 years, so information on all objects in state and province museums are gathered in the digital database with the use of the software register.

According to the 2014 revision to the law, the guidelines and instructions for the registration and information database have been amended, and it was decided that information will be saved equivalently in the registration and information databases at each level of soum, district, and province and Ulaanbaatar City.

Today, three software programs are being used for the digital database of tangible and intangible cultural heritage. 


\section{Database of Historical and Cultural Movable Heritage}

"RCH" or "Registration of Cultural Heritage" software was created as two types, based on one prototype. The software "RCH" or "Registration of Cultural Heritage" was installed in museums. Based on the software $\mathrm{RCH}$, the " $\mathrm{RCH}$ data processing software" received registration and information from 42 museums and processed the gathered information. Registrations done by the software $\mathrm{RCH} 2.0$ are received in the registration and information state database by the internet network and saved in the database.

As of today, a total of 42 organizations involved in the registration and information state database of cultural heritage and its network are sending their registrations in continuously (Fig. 3).

The software RCH is gathering data according to 55 questions in six parts (Center of Cultural Heritage, Culture and Art Committee. Ministry of Education, Culture and Science 2010: 2).

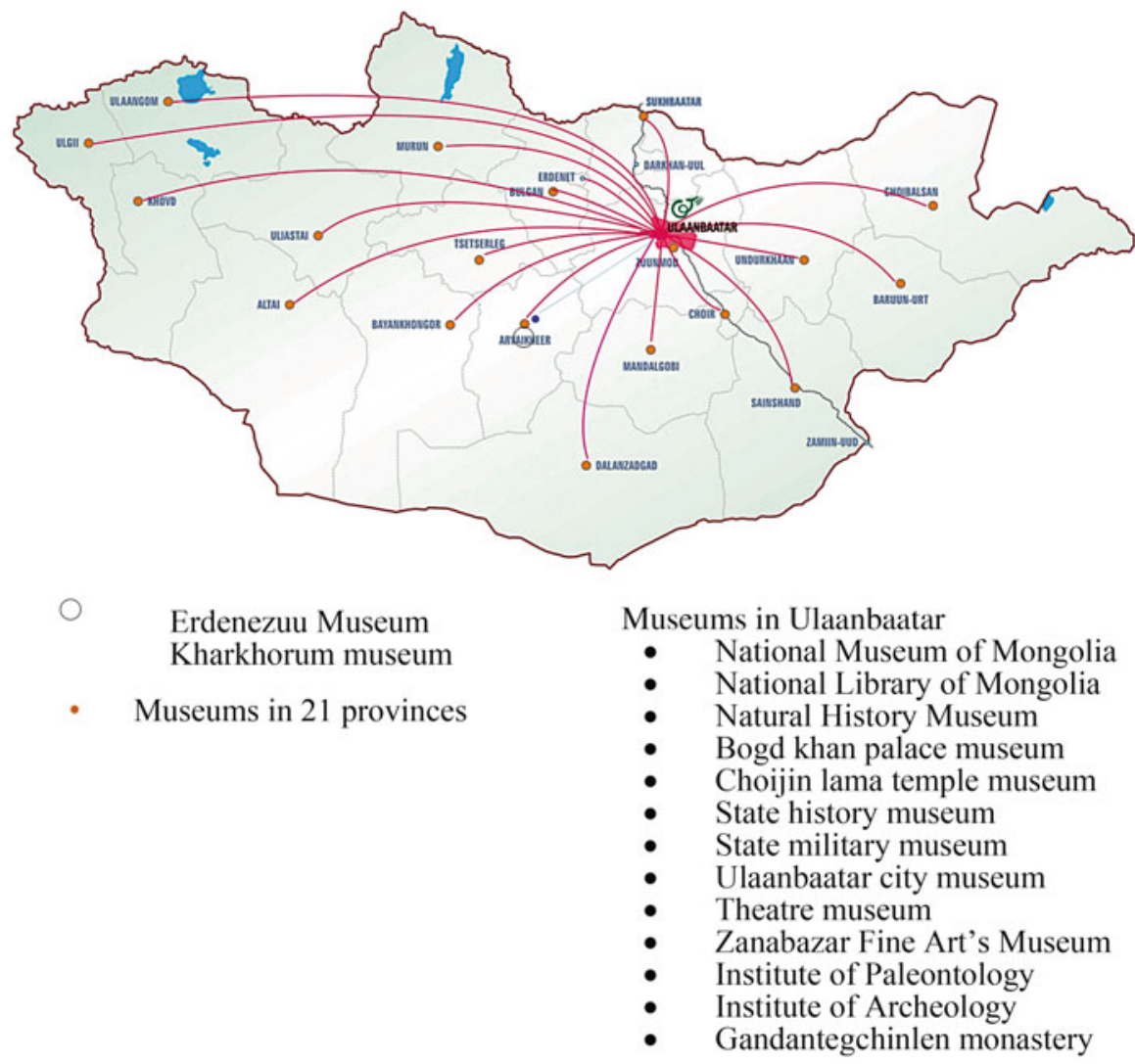

Fig. 3 Network built between Center of Cultural Heritage and state and provincial 42 museums 
(1) Art and artistic

1. Painting/every type of art painting, thangka painting, drawing, etc.

2. Sculpture/cast sculpture with all kinds of artistic value, relief and bas-relief, glass and ceramic art (ceramics), papier maché, etc./

3. Carving/crafted workmanship in all kinds of materials, such as wood and stone

(2) Historic

1. Artifacts related to historic persons or individuals/Choibalsan's watch, Yu. Tsedenbal's bag, D. Ravjaa's brush, etc.

2. Documents, audio and video recording/license, certificate, resolution, all kinds of tapes, films, recordings, CDs, etc.

3. Books and stationery/all kinds of texts, imprints, stationery, maps, etc.

(3) Ethnographic

1. Livestock transport/saddles, bridles, halters, strangling, lassoes, saddles, covers, feeding-bottles, collars, etc.

2. Hunting, farming/flint guns, leaden bullets, call-animal, plows, pans, sieves, etc.

3. Family housing, interior furniture/household items, furniture, dishes, buckets

(4) Religious

1. Deities/thangka paintings and forgotten nagtan $^{1}$ and gartan, ${ }^{2}$ printed or imprinted paintings, icons

2. Textile art/tapestries, embroidery, and laminated textiles

3. Casts/all kinds of religious large and small castings

(5) Archaeological

1. Stone tools/plates and billets, bread-like blades, etc.

2. Accessories and artifacts/earrings, necklaces, rings, belt ornaments, hair ornaments, animal casted figures, etc.

3. Husbandry artifacts/pottery and ceramic utensils, cups, plates, cereal bleached board stone and mortar/Stone and Bronze Age artifacts, etc.

(6) Natural

1. Mammals

2. Plants

3. Birds

\section{Specifics of the Software RCH}

- Detailed information on museum objects is gathered, and it is possible to aggregate, review, process, and print the registrations.

- Registrations can be linked with photographs of museum objects. 
- Information transferred by network can be classified as secure and kept in the data center.

- With the help of the software $\mathrm{RCH}$, we created a united network and provided state and provincial museums the following domain address: www.monheritage. $\mathrm{mn}$. With the use of this network and domain address, state and provincial museums are transferring their objects' registrations and information to the registration and information state database of cultural heritage.

- Every correction in an object's registration will be automatically downloaded and saved in the server.

As of today, 45,645 names and 65,211 objects have been registered in the software $\mathrm{RCH}$.

In August 2012, registration software was developed for the state inventorying of museum objects, and it was installed in 42 state and provincial museums and organizations. The registration software is based on the questions from the notebook "General registration for museum objects and artifacts," which allows the database to process data from different categories and periods and to adjust additional questions for each museum. After installing the initial version of the software, it was adjusted and improved 15 times, and each museum received these updates. According to the 140th order of the Ministry of Finance of Mongolia, the regulation "Fixing new value for historical and cultural heritage and museum objects" was approved. The registration software then added a way to save the value of each heritage. In the frame of state inventorying, 97,979 names and 229,976 objects in 42 state and provincial museums were registered in the software "Register" (Fig. 4).

\section{Database of Historical and Cultural Immovable Properties}

According to joint decision 299/324/111 by the Ministry of Finance, the Ministry of Education, Culture and Science, and the Ministry of Professional Inspection on September 27th of 2006, the inventorying work for "Historical and cultural immovable heritage, such as tombs, tumuli, petroglyphs, inscriptions, stone monuments, temples and monasteries, ruins of ancient cities, and historic stupa and ovoo" 3 was approved and is being implemented by the Center. As of 2015, a total 32,124 historical and cultural immovable properties from 3,100 cultural sites in 15 provinces have been registered (Fig. 5), and the information collected is kept in the provincial database and registration and information state database of cultural heritage.

According to the "Protection Law for Cultural Heritage" historical and cultural immovable properties were classified as 11 types regardless of their ownership. Based on the registration form, the software "RICH" or "Registration of Immovable Cultural Heritage" was created. The objective of this software is to create a state database of historical and cultural immovable properties and process the gathered data. The software "RICH" gathers data according to 35 questions in seven parts. These are as follows (Enkhbat et al. 2014: 103-131): 
Fig. 4 Classification of the objects registered
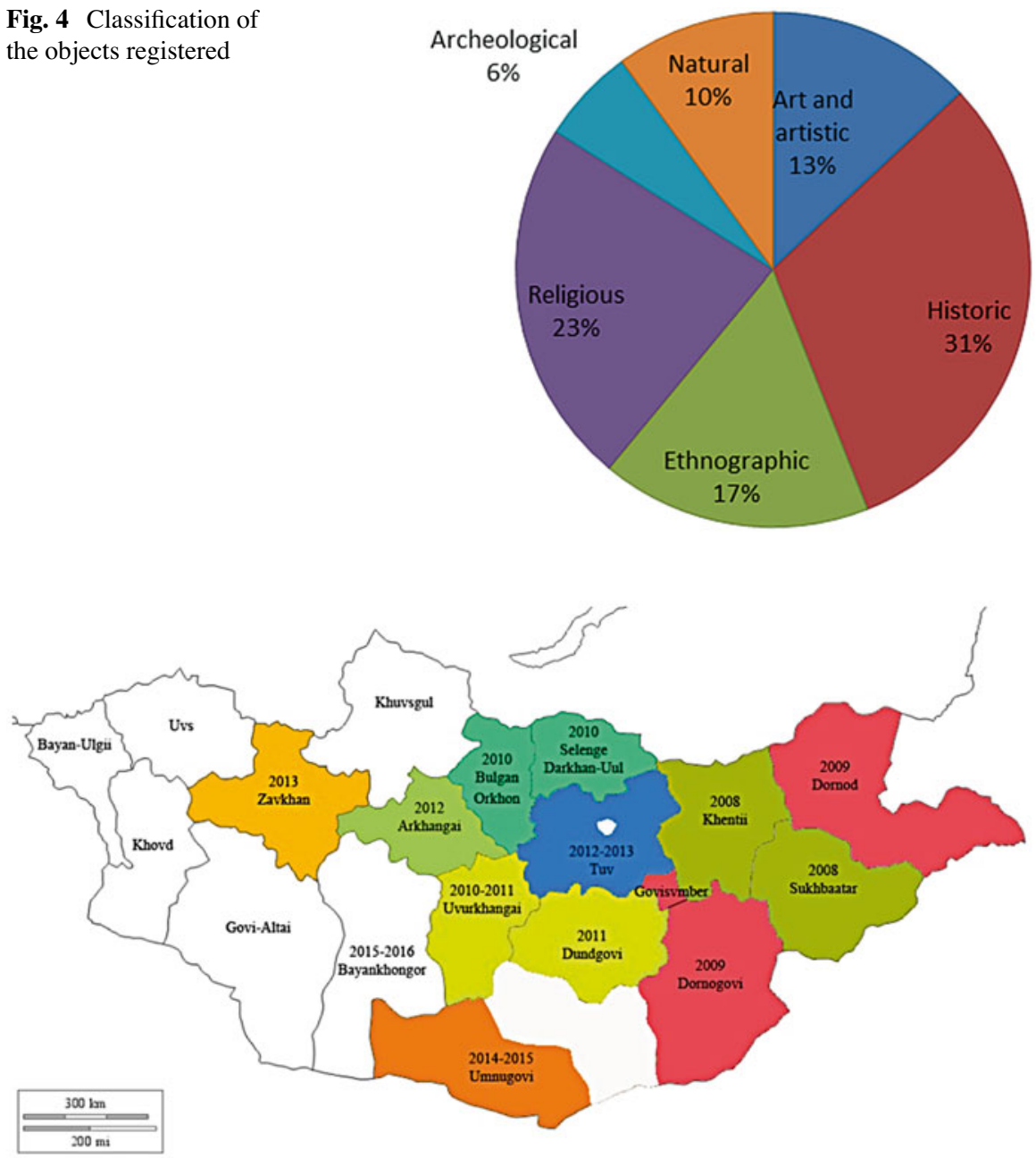

Fig. 5 Registration and inventorying of historical and cultural immovable properties (2008-2018)

\section{Classifications Used in the Software RICH}

1. Stone Age sites

2. Petroglyphs and other rock art

3. Tombs, tumulus, sacrificial structure

4. Architectural sites

5. Monuments

6. Places of mineral extraction and manufacturing

7. Natural sites 


\section{Questions of the Software RICH}

1. Places with findings of ancient flora

2. Places with findings of ancient fauna

3. Petrified wood

4. Fossils

5. Stone Age settlements and crafting places

6. Sites with stone tools

7. Ochre and ink petroglyphs

8. Carved petroglyphs

9. Symbols

10. Inscriptions

11. Deities paintings

12. Tombs and graves

13. Cave tombs

14. Tumuli

15. Sacrificial structures

16. Ovoo

17. Ruins of ancient cities and walls

18. Ruins of temples and monasteries

19. Monasteries and temples

20. Stupa

21. Architectural buildings

22. Fortresses

23. Drainage structures

24. Walls

25. Deer stones

26. Manstone monuments

27. Inscribed monuments

28. Animal-figured stones

29. Sealed monuments

30. Stone monuments

31. Inscribed commemoration monuments

32. Places used for mining

33. Places used for manufacturing of ceramics

34. Places used for agriculture

35. Zel stones or balbals ${ }^{4}$

\section{Specifics of the Software RICH}

- Every immovable property will be registered in the software RICH and numbered by the state registration and information database.

- It registers and collects the information related to historical and cultural immovable properties, and the collected data is then processed.

- It marks the GPS information of the immovable property on the map and includes a photo. 


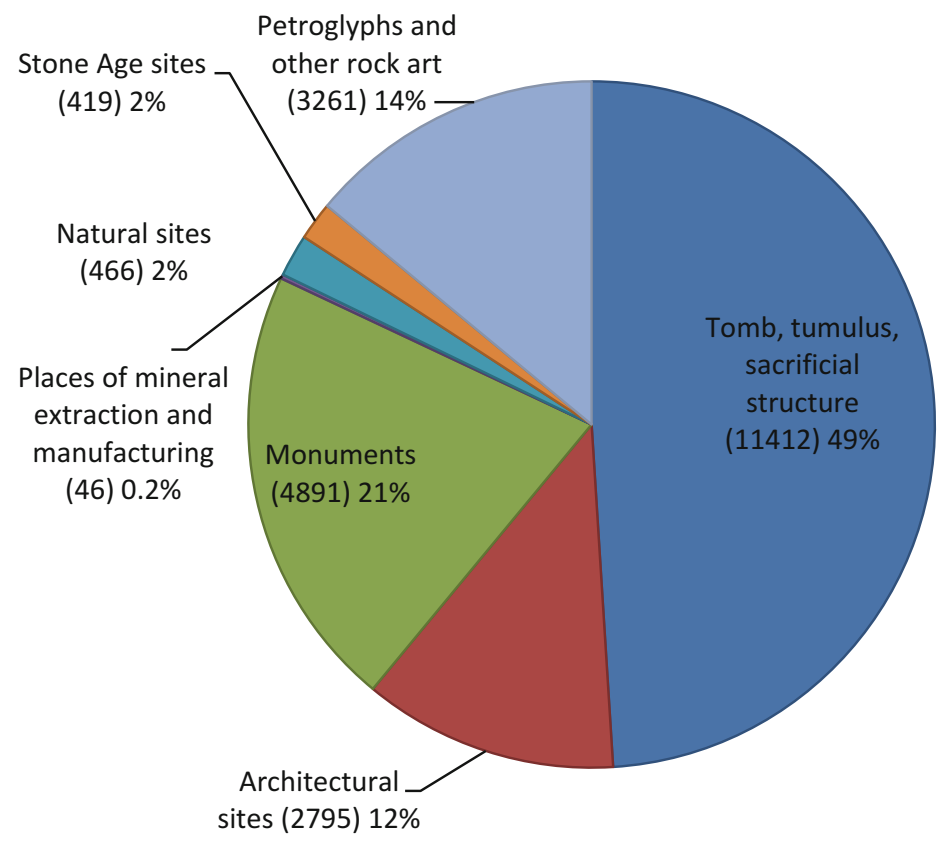

Fig. 6 Classification of the historical and cultural immovable properties registered

- Data from the registration and information state database can be searched and used in statistical analysis relating to the historical and cultural immovable properties in the territory of Mongolia.

As of 2015, 23,290 historical and cultural immovable properties in 2,031 cultural sites have been registered in the software RICH (Fig. 6).

\section{Registration and Information Database of Intangible Cultural Heritage}

Figure 7 shows the national registration and information system of intangible cultural heritage in Mongolia.

The Protection Division for ICH receives the registration and information of $\mathrm{ICH}$ and its bearers in the state database according to the form "Registration of ICH and its bearers" since 2010 (Table 1).

The rules for the registration and information database of $\mathrm{ICH}$ were approved and a manual was published. A training session and workshop was organized for local registration officers and cultural staff, aiming to improve the creation of the registration and information database and capacity building. 


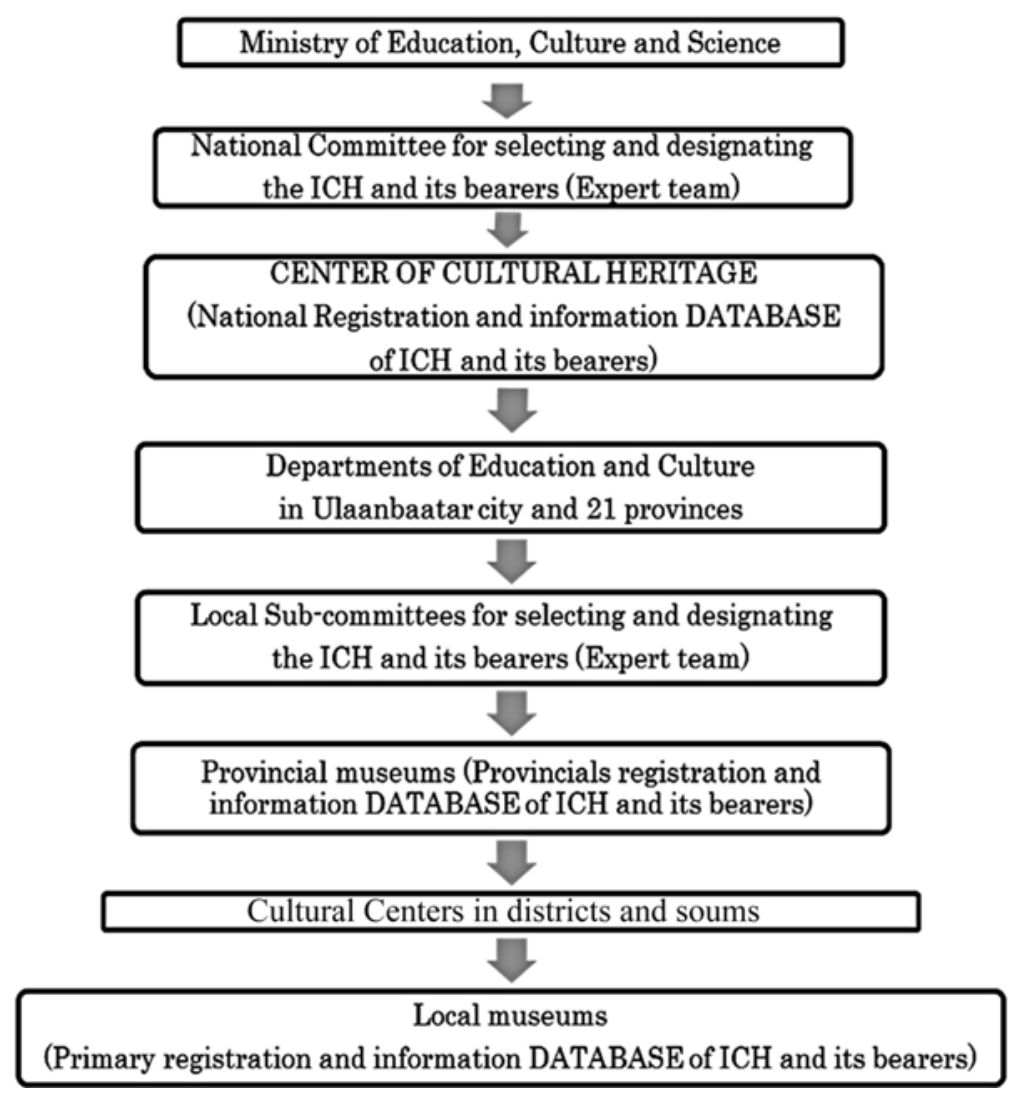

Fig. 7 Establishment of the National Registration and Information System of ICH in Mongolia

Table 1 ICH registration cycle

\begin{tabular}{|c|c|c|c|c|c|c|c|c|}
\hline \multicolumn{3}{|c|}{ Cycle I } & \multicolumn{3}{|c|}{ Cycle II } & \multicolumn{3}{|c|}{ Cycle III } \\
\hline $\begin{array}{l}\text { Month } \\
1\end{array}$ & $\begin{array}{l}\text { Month } \\
2\end{array}$ & $\begin{array}{l}\text { Month } \\
3\end{array}$ & $\begin{array}{l}\text { Month } \\
4\end{array}$ & $\begin{array}{l}\text { Month } \\
5\end{array}$ & $\begin{array}{l}\text { Month } \\
6\end{array}$ & $\begin{array}{l}\text { Month } \\
7\end{array}$ & Month 8 & Month 9 \\
\hline \multicolumn{3}{|c|}{$\begin{array}{l}\text { Acceptance of } \\
\text { applications from } \\
\text { communities, groups and } \\
\text { individuals at the local } \\
\text { Departments of } \\
\text { Education and Culture in } \\
\text { provinces and Cultural } \\
\text { Centers in soums }\end{array}$} & \multicolumn{2}{|c|}{$\begin{array}{l}\text { Evaluation and } \\
\text { Selection by } \\
\text { Provincial } \\
\text { "Sub- } \\
\text { committees for } \\
\text { Selecting and } \\
\text { Designating } \\
\text { ICH and its } \\
\text { Bearers" }\end{array}$} & \multicolumn{2}{|c|}{$\begin{array}{l}\text { Elaboration and } \\
\text { consolidation by } \\
\text { the Center of } \\
\text { Cultural } \\
\text { Heritage under } \\
\text { the Ministry of } \\
\text { Education, } \\
\text { Culture, and } \\
\text { Science }\end{array}$} & $\begin{array}{l}\text { Selection and } \\
\text { designation } \\
\text { by "National } \\
\text { Committee } \\
\text { for Selecting } \\
\text { and } \\
\text { Designating } \\
\text { ICH and its } \\
\text { Bearers" }\end{array}$ & $\begin{array}{l}\text { Approval by } \\
\text { the Ministry } \\
\text { of Culture, } \\
\text { Sports and } \\
\text { Tourism }\end{array}$ \\
\hline
\end{tabular}




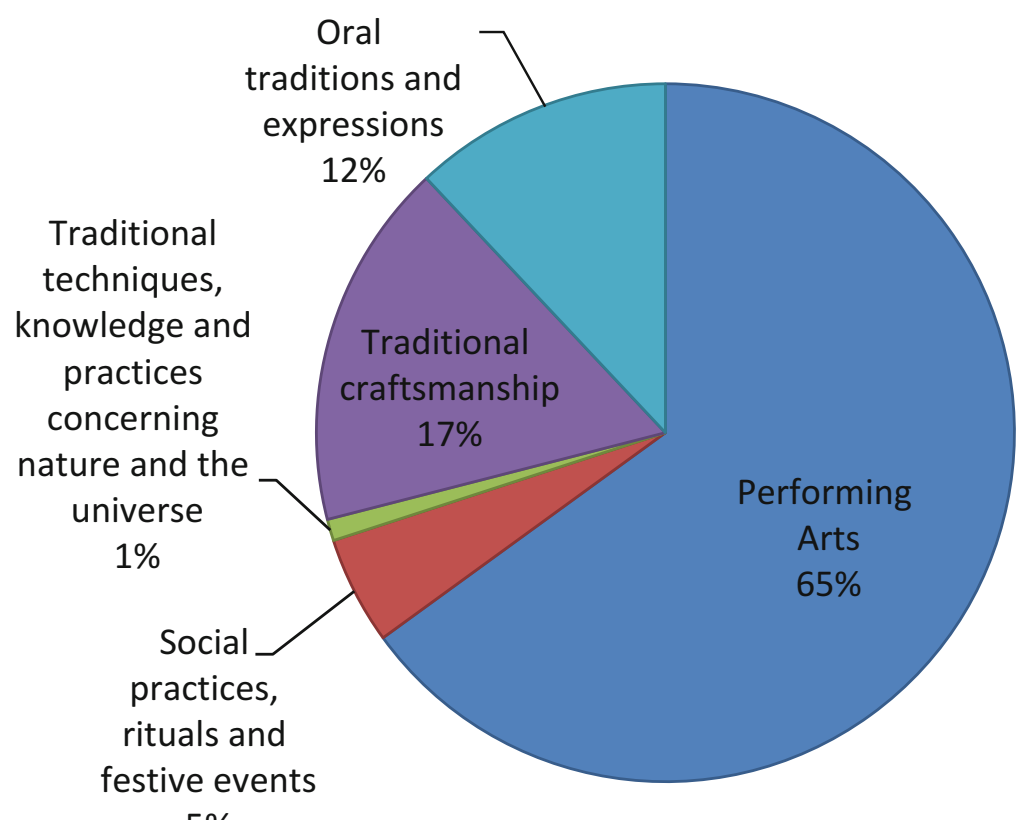

$5 \%$

Fig. 8 Registration census of ICH bearers by domain (2013): 7206 ICH bearers by five classifications

Registration work of ICH covered 329 soums and 9 districts and increased the number of individuals identified as ICH bearers to 7,206. The results of the registration census are a valuable asset gathered as a source to further elaborate the shortand long-term objectives, policies, and programs for safeguarding and transmitting ICH (Figs. 8 and 9) (Yundenbat and Tuul 2012: 90).

Since 2013, registration and information of ICH has been saved in the digital database. It is a priority for the information on $\mathrm{ICH}$ bearers to be saved in the digital database. As of today, $568 \mathrm{ICH}$ bearers' information is saved in the digital database. In the future, intangible cultural heritage elements will be saved in this database.

\section{Problems in the Creation of a Digital Registration and Information Database of Cultural Heritage}

Problems related to the creation of database of cultural heritage can be summarized as follows:

\section{Problems Related to the Software RCH and Register}

- The budget for registration and documentation of museum objects is inadequate. 


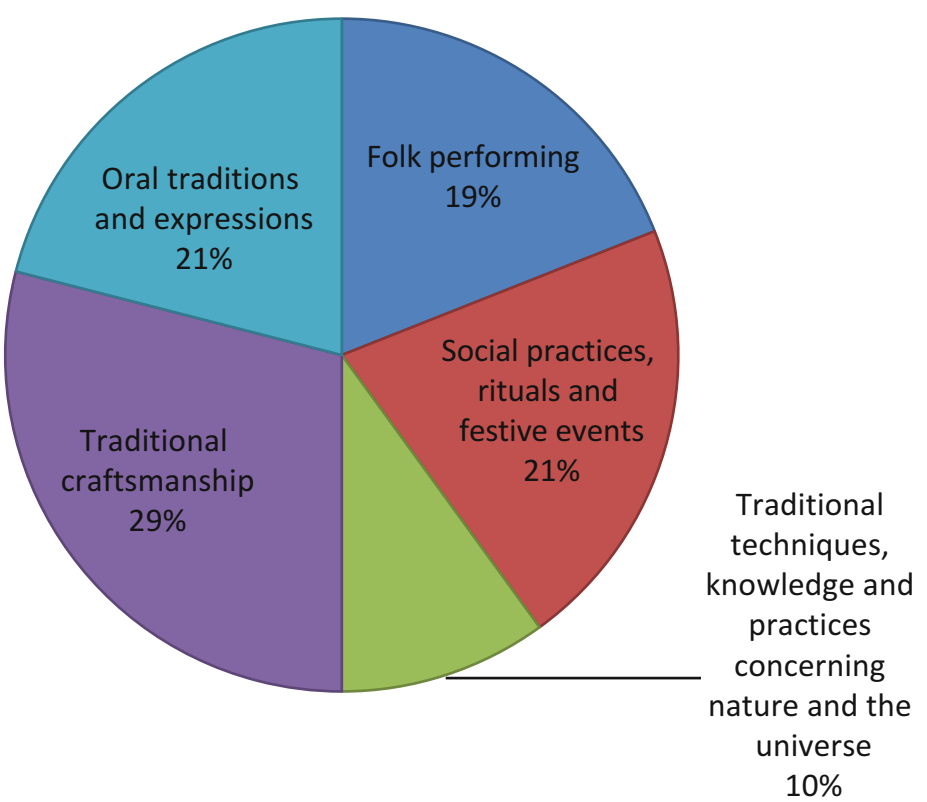

Fig. 9 Registration census of ICH elements by domain (2013): 104 ICH elements by five classifications

- Equipment and human resources for registration of museum objects are inadequate.

- Services of the registration and information database and relevant registration officers have just been established.

- There is a lack of experience in computer and software use, leading to computer viruses.

- There are occasional losses of data, system failures, etc.

\section{Problems Related to the Software RICH}

- Delayed information uploading.

- There is a limited data range because data are uploaded only by the Center of Cultural Heritage, which are gathered during the research and inventorying of historical and cultural immovable properties.

- Only some of the early paper-based registration forms in the registration and information database have been uploaded.

- Other research institutes did not participate in using this software.

- It is necessary to encourage other research institutes to participate in using the software and gathering the data.

- All data related to historical and cultural immovable properties in the registration and information state database should be saved in the software RICH. 


\section{Problems Related to the Registration of ICH Bearers}

- Due to difficulties in documentation equipment, there are some problems in the everyday activities of the division and the creation of a database.

- However, a registration of ICH bearers started in the provinces and Ulaanbaatar City in 2010. Registration is not adequately performed in accordance with the registration form due to inadequate methods, equipment, and finances.

\section{New Technologies Used in the Digital Database}

\subsection{Three-Dimensional Documentation}

Three-dimensional documentation for movable and immovable heritage started at the Center in 2008. Since then, several documentation works have been done in collaboration with the National Research Institute for Cultural Properties (NRICP), Tokyo, and Doshisha University and the processed data of 3D documentation have been saved in the registration and information state database of cultural heritage (Fig. 10).

\subsection{Improvement of Diagnostic Equipment of the Center of Cultural Heritage}

Aiming to make digital documentation for cultural heritage, historical and cultural immovable properties, and intangible heritage and to analyze the material composition of museum objects and archeological artifacts, the Center initiated the project

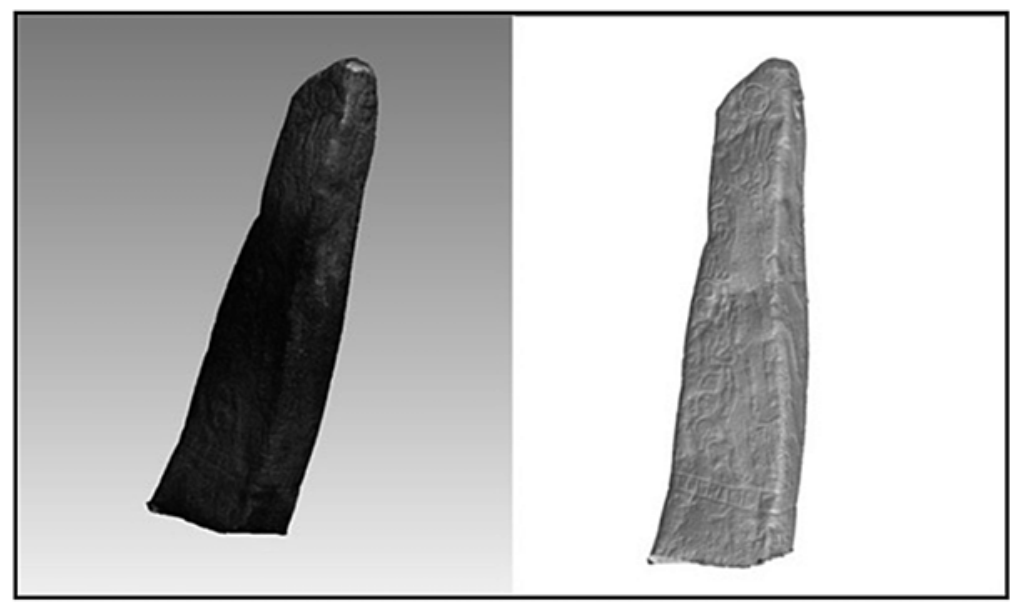

Fig. 10 Deer stones of Dund Jargalantyn am in Omnodelger soum of Khentii Province 


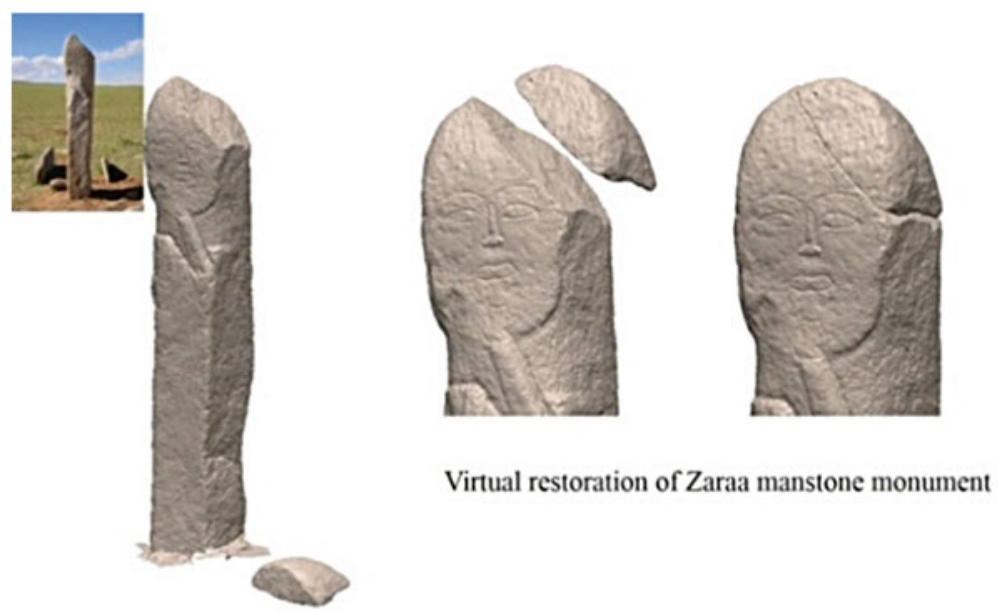

Fig. 11 Visual restoration of Zaraa manstone monument

"Improvement of Diagnostic Equipment of the Center of Cultural Heritage" in 2009 and it was implemented in 2013 through Japanese Cultural Grant Aid. Under the scope of the project, the Center was provided with a portable 3D digitizer (Vivid 9i). Three-dimensional documentation of museum objects and historical and cultural immovable properties is being undertaken with the use of Vivid 9i and the collected data are saved in the digital database. Based on gathered data from 3D measurements, virtual restoration works have been done for some immovable properties (Fig. 11).

\subsection{National Project for Digitization of Cultural Heritage-2}

The implementation of the "National Project for Digitization of Cultural Heritage" (2006-2008) basically covered museums; it was not dedicated to and did not cover the creation of a registration and information database for historical and cultural heritage and intangible cultural heritage through the state.

For this reason, the Government of Mongolia has approved the "National Project for Digitization of Cultural Heritage-2" by its 215th decision in 2014, aiming to register and document cultural heritage, to take control of conservation and preservation of cultural heritage, to create a digital database for tangible and intangible cultural heritage, and to improve the system used in the registration and information database of cultural heritage.

The objectives of the project is to create a registration and information database of cultural heritage at the level of soum, province, and Ulaanbaatar City and related to this, to provide and decide necessary matters, such as human resources, budget, and equipment. Every soum and province will register and document the tangible 


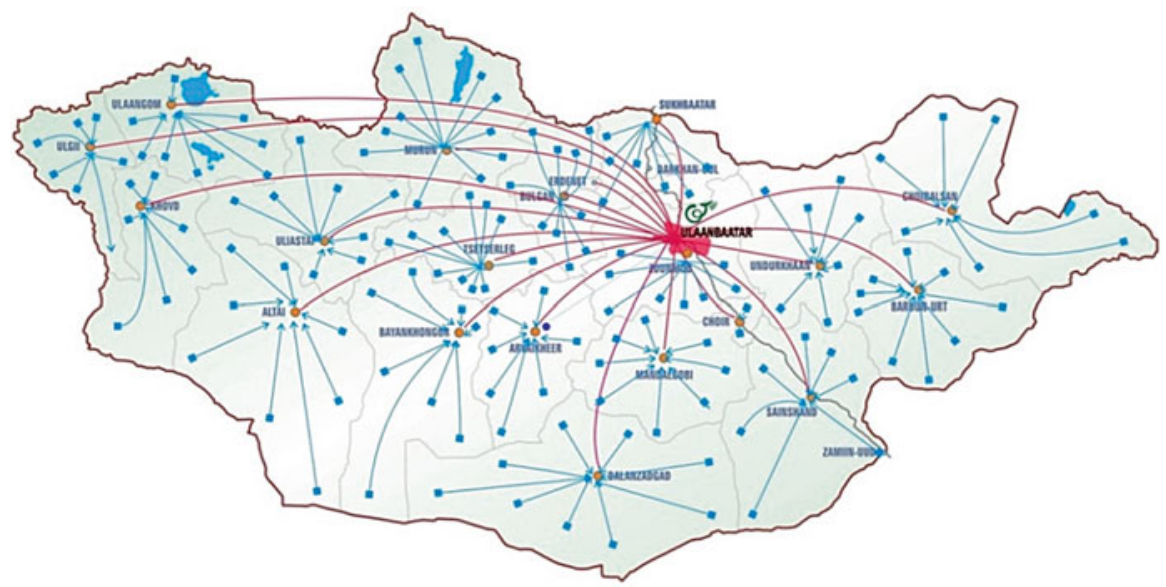

Fig. 12 Registration and information database of cultural heritage at the level of soum, province, and Ulaanbaatar City under the "National Project for Digitization of Cultural Heritage-2"

and intangible cultural heritage in their territory and create a registration and information database using the gathered data (Fig. 12). It will serve to improve the registration and documentation of tangible and intangible cultural heritage, as well as to create a registration and information database;

For museum objects and artifacts, it will improve the activity of the registration and information database in museums and research organizations; it will activate the research and study of objects and to use the research results in the registration; and it will improve the registration and documentation of museum objects and responsibility.

For historical and cultural immovable properties, it will make cadastral confirmation of historical and cultural immovable property, selected to be in the protection of "State," "Province," or "Ulaanbaatar City" by the decision of the Government of Mongolia; it can number the historical and cultural immovable property registered in the registration and information database; and it serves to organize registration and documentation work for historical and cultural immovable properties through the territory of soum and province.

For intangible cultural heritage, it will improve the registration system of intangible cultural heritage and create a registration and information database of intangible cultural heritage; it helps to increase the number of ICH elements in the list of Need of Urgent Safeguarding and Representative List of Intangible Cultural Heritage.

\section{Notes}

1. Thangka paintings on black background are called nagtan.

2. Thangka paintings on white background are called gartan.

3. Ovoo is a sacred cairn found in Mongolian shamanic religious traditions, usually made from rocks or wood. Ovoo is often made at the top of mountains and in high places. 
4. Zel stone or balbal is an ancient worshiping stone without description (plain stone) which situated next to the burial. This kind of stone is one part of the burial complex that continues a long distance of about $1 \mathrm{~km}$ with many separated pieces (defends its burials type). Many of them are ordered and especially directed to the south east direction which means direction of sunrise.

Open Access This chapter is distributed under the terms of the Creative Commons AttributionNonCommercial 4.0 International License (http://creativecommons.org/licenses/by-nc/4.0/), which permits any noncommercial use, duplication, adaptation, distribution and reproduction in any medium or format, as long as you give appropriate credit to the original author(s) and the source, provide a link to the Creative Commons license and indicate if changes were made.

The images or other third party material in this chapter are included in the work's Creative Commons license, unless indicated otherwise in the credit line; if such material is not included in the work's Creative Commons license and the respective action is not permitted by statutory regulation, users will need to obtain permission from the license holder to duplicate, adapt or reproduce the material.

\section{References}

Center of Cultural Heritage, Culture and Art Committee. Ministry of Education, Culture and Science. 2010. Muzein burtgel-medeelliin sanch nart zoriulsan "Soyolyn uviin burtgel medeelliin sang burduulekh ni” seminar. Ulaanbaatar: Admon Printing Co. Ltd. (In Mongolian).

Enkhbat, G., B. Altansukh, G. Ankhsanaa, and T. Erdenetsogt. 2014. Tuukh soyolyn ul hudlukh dursgalyn uzleg, toollogyn burtgeliin RICH programyn garyn awlaga. Ministry of Education, Culture and Science, Center of Cultural Heritage. Ulaanbaatar: Admon Printing Co.Ltd. (In Mongolian).

Yundenbat, C., and G. Tuul. 2012. Soyolyn biyet bus uwiig burtgen barimtjuulakh, burtgel medeelliin san burduulekh arga zui. Ministry of Education, Culture and Science, Center of Cultural Heritage. Ulaanbaatar: Soyombo Printing Co.Ltd. (In Mongolian). 